\title{
Kapulukaya Barajı Aşağı Havza'sı Sediment Örneklerinde Ağır Metal Kirlilik Düzeylerinin Değerlendirilmesi (Kızılırmak, Kırıkkale)
}

\author{
Gökben BAŞARAN KANKILIÇ* \\ Kırıkkale Üniversitesi, Fen Edebiyat Fakültesi, Biyoloji Bölümü, 71450 Kırlkkale, Türkiye \\ (ORCID: 0000-0001-7551-4899)
}

\begin{abstract}
Öz
Bu çalışmada Mayıs 2013-Șubat 2014 tarihleri arasında Kızılırmak Nehri’nin Kırıkkale il sınırları içerisinde kalan kısmında belirlenen altı istasyondan alınan sediment örneklerinde ağır metal kirlilik düzeyleri incelenmiştir. Al, $\mathrm{Fe}, \mathrm{As}, \mathrm{Cr}, \mathrm{Ni}, \mathrm{Pb}, \mathrm{Zn}, \mathrm{Cd}, \mathrm{Hg}$ elementlerinin konsantrasyonları ICP-OES cihazı kullanılarak belirlenmiştir. Sonuçlara göre, Fe tüm istasyonlarda en yüksek konsantrasyonda birikim gösteren element olurken $\mathrm{Hg}$, S1 istasyonu hariç en düşük konsantrasyonda birikmiştir. Çalışmanın yapıldığı dönemde Kırıkkale iline ait atık su arıtma tesisi bulunmaması sebebiyle kanalizasyon atıkları doğrudan Kızılırmak Nehri’ne bırakılmaktaydı. Atık suyun Kızılırmak Nehri'ne boşaltıldığı nokta, çalışmanın gerçekleştirildiği istasyonlardan S3 ile S4 arasında yer almaktadır. Buna göre ilk üç istasyon (S1, S2, S3) ve son üç istasyon (S4, S5, S6) karşılaştıııldı̆̆ında ortalama değerlerin Hg hariç arttı̆̆ı belirlenmiştir. Mevsimsel olarak anlamlı farklılık sadece Zn elementi için ilkbahar ile sonbahar ve ilkbahar ile kış arasında tespit edilmiştir $(\mathrm{p}<0,05)$. Sediment kalite rehberinde belirtilen değerler kullanılarak ağır metal konsantrasyonları canlılık açısından değerlendirilmiştir. As, Ni element konsantrasyonlarının sedimentte sıklıkla yaşayan ve sedimentten beslenen organizmalar üzerinde zararlı etkilere yol açabilmesi muhtemel görülmüştür. Ayrıca Pb element konsantrasyonunun S4 istasyonunda canlılık açısından zararlı etkiler açığa çıkarabileceği tespit edilmiştir.
\end{abstract}

Anahtar kelimeler: Kızılırmak, ağır metal, su kirliliği, sediment, sediment kalite rehberi.

\section{Assessment of Heavy Metal Pollution Levels in Sediment Samples of Lower Catchment Area of Kapulukaya Reservoir (Kızılırmak, Kırıkkale)}

\begin{abstract}
In this study, heavy metal pollution levels were investigated in the sediment samples which taken from six different sites in the Kizllırmak River in Kırıkkale province, between May 2013 and February 2014. The concentrations of $\mathrm{Al}, \mathrm{Fe}, \mathrm{As}, \mathrm{Cr}, \mathrm{Ni}, \mathrm{Pb}, \mathrm{Zn}, \mathrm{Cd}$ and $\mathrm{Hg}$ were determined by using ICP-OES. According to the results, Fe was the element showing the highest concentration in all stations, while $\mathrm{Hg}$ was the element with lowest concentration except S1 site. During the study, seweage effluents were left directly to Kizllirmak River due to the lack of waste water treatment plant belonging to Kırıkkale province. The point where waste water is discharged to Kizılırmak River is located between S3 and S4 sites where the study is carried out. Accordingly to the results, when the first three stations (S1, S2, S3) and the last three stations (S4, S5, S6) were compared, it was found that the average values increased except $\mathrm{Hg}$. Seasonally significant difference was found only for $\mathrm{Zn}$ element between spring and autumn and spring and winter seasons $(\mathrm{p}<0.05)$. Heavy metal concentrations levels were evaluated for organisms using the values specified in the sediment quality guideline. The concentrations of As, Ni are likely to have harmful effects on sediment-dwelling organisms. In addition, it was determined that $\mathrm{Pb}$ element concentration could cause harmful effects on viability in S4 station.
\end{abstract}

Keywords: Kızılırmak, heavy metal, water pollution, sediment, sediment quality guideline.

"Sorumlu yazar: gokbenbasaran@kku.edu.tr

Geliş Tarihi: 02.07.2019, Kabul Tarihi: 23.07.2019 


\section{Giriş}

Sucul sistemlerde biriken ağır metallerin doğal süreçler (erozyon, kayaçların ayrışması vb.) ve insan kaynaklı faaliyetler (tarım faaliyetleri, madencilik, endüstriyel, rafineri ve evsel atıklar, ulaşım, fosil yakıt kullanımı vb.) ile sisteme dahil olduğu bilinmektedir [1]. Son yüzyılda hızlı nüfus artışı, hızlı ve çarpık kentleşme, plansız sanayileşme nedeniyle doğal süreçlere kıyasla insan kaynaklı faaliyetler sonucu sucul sisteme dahil olan ağır metal miktarı daha fazla olmuştur [2,3]. Ağır metaller, biyolojik olarak bozunabilir değildir yani bulundukları ortamda uzun süre kalabilirler. Yaygın șekilde bulunurlar. Düşük konsantrasyonlarda dahi toksik etki gösterebilirler, biyoakümüle ve biyomagnifiye olabilirler. Tüm bu nedenlerden dolayı, ağır metaller çevre kirliliği ve canlı sağlı̆̆ 1 açısından ciddi kaygılar oluşturmaktadır[4-6].

Doğal süreçler ve insan kaynaklı faaliyetler ile sucul siteme dahil olan ağır metaller, su, sediment ve canlı organizmalar gibi sucul ekosistemin öğeleri arasında dağılırlar. Bununla birlikte ağır metallerin sahip olduğu bazı özellikler nedeniyle, çok az miktarı suda serbest iyon halinde kalırken büyük bir kısmı sedimentte çökelir [7]. Bu nedenle sediment, ağır metallerin yerleşmesi ve taşınması için bir birikim alanı olarak rol oynar. Diğer taraftan sediment, sistemin temel bir bileşeni olarak çoğu sucul organizma için yaşam, beslenme, yumurta bırakma, yavru gelişim alanı olarak da görev yapmaktadır. Böylece sediment, su sütunu, organizmalar ve son olarak bu canlıları tüketen insanlar açısından kirleticilerin potansiyel kaynağını oluşturmaktadır [8-11]. Sediment yoluyla metal geçişi bazı organizmalar açısından önemli bir metal kaynağı olmakla birlikte [12]diğer taraftan sedimentteki ağır metal birikiminin organizmalar üzerine olumsuz etkilerinin de olduğu gösterilmiștir $[8,13,14]$. Bu nedenle sucul yaşamı korumak kadar tatlısu ekosisteminin biyolojik bütünlüğünü sürdürme noktasında sediment kalitesinin korunması da önemli bir nokta olarak dikkat çekmektedir [15]. Dolayısıyla sediment örneklerinin analizi, bir bölgedeki ağır metal kirlilik düzeylerinin belirlenmesinde önemli bir gösterge olarak karşımıza çıkmaktadır

Türkiye'nin en uzun nehri olan Kızılırmak, havza üzerinde insan faaliyetleri sonucu oluşan (endüstriyel, tarımsal vb.) farklı nitelikteki kirleticilere yoğun şekilde maruz kalmaktadır. Kızılırmak Nehir'i üzerinde Hirfanlı, Kesikköprü ve Kapulukaya barajlarından oluşan önemli bir baraj zinciri bulunmaktadır. Bu çalışmada baraj zincirinin son halkasını oluşturan Kapulukaya Barajı setinin aşağısından seçilen istasyonlarda yüzeyden alınan sediment örneklerindeki ağır metal miktarının mevsimsel olarak belirlenmesi amaçlanmıştır. Ayrıca mevcut durum sediment kalite rehberleri ile karşılaştırılarak değerlendirilmiştir.

\section{Materyal ve Metot}

\section{1. Çalışma Alanı}

Kızılırmak Havzası $\left(78.180 \mathrm{~km}^{2}\right)$ içerisinde yer alan, $1355 \mathrm{~km}$ uzunluğundaki Kızılırmak Nehri, Türkiye'nin en uzun akarsuyudur. Havzada elektrik üretimi, sulama, taşkından koruma, içme suyu eldesi gibi farklı amaçlarla kullanılan toplam 33 baraj bulunmaktadır [16]. Bunlardan Kızılırmak Nehri'nin Kırıkkale il sınırları içerisinde, Orta Kızılırmak Havzası'nda yer alan Kapulukaya Barajı, Türkiye'nin önemli barajlarından olan yine aynı havza üzerinde kurulu, Hirfanlı ve Kesikköprü Barajlarının son halkasını oluşturmaktadır. Çalışma alanı olarak Kapulukaya Barajı Aşağı Havzası' dan itibaren yaklaşık 30 km'lik bir hat boyunca altı farklı örnekleme istasyonu (S1, S2, S3, S4, S5 ve S6) seçilmiştir (Şekil 1, Tablo 1). Örnekleme noktalarının seçiminde atıksu noktaları, tarım arazilerinin olup olmaması, yerleşim bölgeleri göz önüne alınmıştır. 


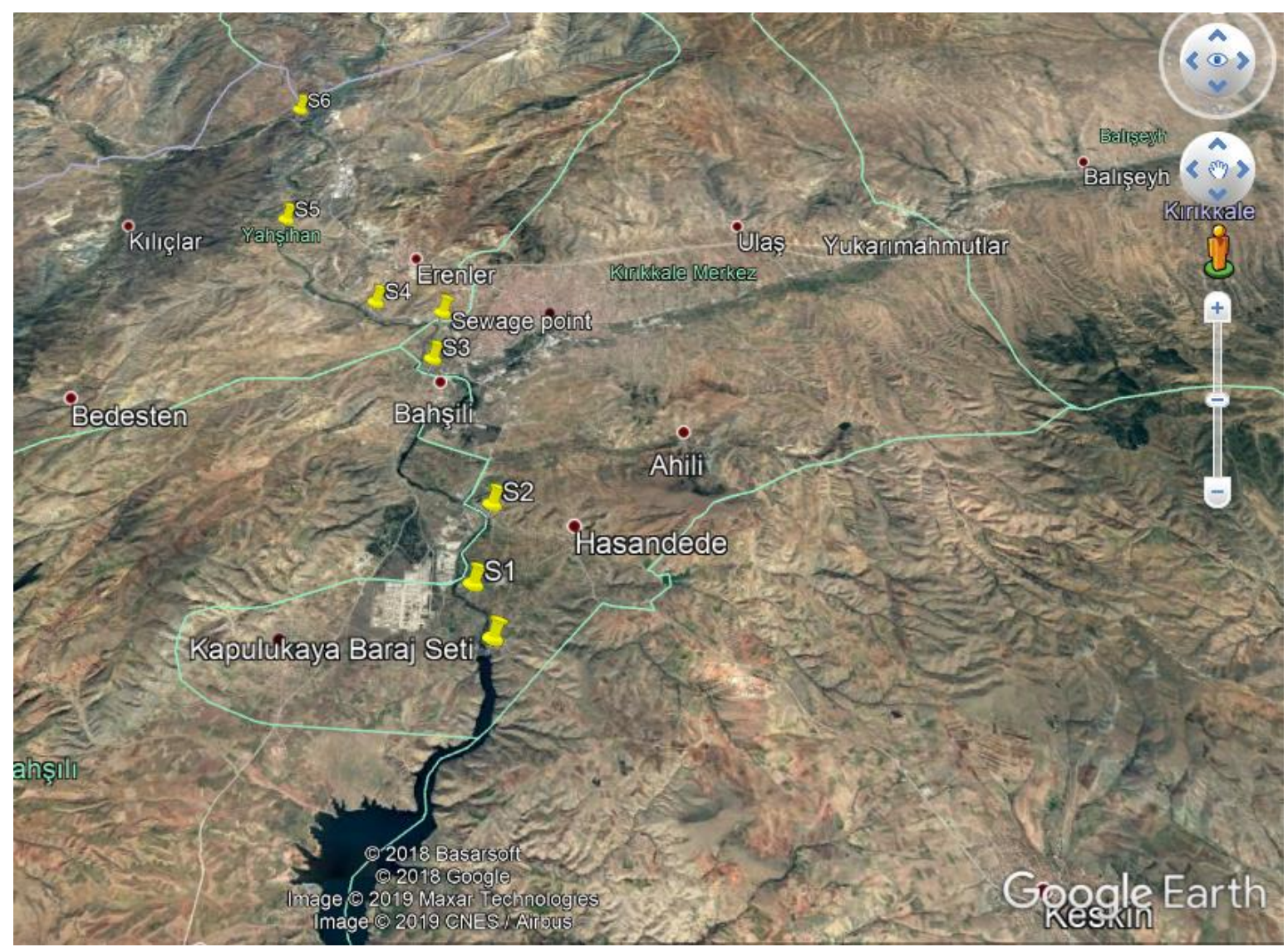

Şekil 1.Kapulukaya Barajı Aşağı Havzası (Kızılırmak) örnekleme istasyonlarının (S1, S2, S3, S4, S5, S6)

Google Earth haritası üzerinde gösterimi

Tablo 1. Örnekleme yapılan istasyonların koordinat ve rakımları

\begin{tabular}{|c|c|c|}
\hline Örnekleme Noktaları & Koordinat & Rakım \\
\hline $\mathrm{S} 1$ & $39^{\circ} 44^{\prime} 42.78^{\prime \prime} \mathrm{K}, 33^{\circ} 28^{\prime} 46.36^{\prime} \mathrm{D}$ & $686 \mathrm{~m}$ \\
\hline $\mathrm{S} 2$ & $39^{\circ} 46^{\prime} 8.45^{\prime} \mathrm{K}, 33^{\circ} 29^{\prime} 8.20^{\prime} \mathrm{D}$ & $683 \mathrm{~m}$ \\
\hline $\mathrm{S} 3$ & $39^{\circ} 49^{\prime} 11.59^{\prime \prime} \mathrm{K}, 33^{\circ} 28^{\prime} 4.05^{\prime} \mathrm{D}$ & $670 \mathrm{~m}$ \\
\hline $\mathrm{S} 4$ & $39^{\circ} 50^{\prime} 33.37^{\prime} \mathrm{K}, 33^{\circ} 26^{\prime} 53.63^{\prime \prime} \mathrm{D}$ & $669 \mathrm{~m}$ \\
\hline $\mathrm{S} 5$ & $39^{\circ} 52^{\prime} 48.79^{\prime \prime} \mathrm{K}, 33^{\circ} 24^{\prime} 50.13^{\prime \prime} \mathrm{D}$ & $682 \mathrm{~m}$ \\
\hline $\mathrm{S} 6$ & $39^{\circ} 56^{\prime} 21.51^{\prime \prime} \mathrm{K}, 33^{\circ} 2449.06{ }^{\prime} \mathrm{D}$ & $665 \mathrm{~m}$ \\
\hline
\end{tabular}

\subsection{Arazi Çalışması ve Örneklerin Hazırlanması}

Örneklemeler, Mayıs 2013 ve Şubat 2014 tarihleri arasında mevsimsel olarak yapılmıştır. Sediment örnekleri, yüzeyden yaklaşı $10 \mathrm{~cm}$ derinlikten üç tekrarlı olarak modifiye polipropilen borular kullanılmak suretiyle alınmıştır. Laboratuvara getirilen sediment örnekleri analiz edilmeden önce derin dondurucuda $-20{ }^{\circ} \mathrm{C}$ de muhafaza edilmiştir. Kompozit haline getirilen örnekler $40-45{ }^{\circ} \mathrm{C}$ 'lik etüvde kurutulduktan sonra, agat havan içerisinde ögütülerek $500 \mu \mathrm{m}$ 'lik elekten geçirilmiştir $[17,18]$.

\subsection{A ğır Metal Analizleri}

Ağır metal analizleri için toplam 0,5 g kurutulmuş sediment örneği vessel olarak adlandırılan tüplere aktarılarak üzerlerine $12 \mathrm{ml}$ nitrik asit:hidroklorik asit $\left(\mathrm{HNO}_{3}: \mathrm{HCl} ; 3: 1\right)$ karışımı eklenmiştir [19]. Mikrodalga çözme sistemi olarak CEM MARS 6 cihazı kullanılmış ve asit hidrolizi için cihazda tanımlı olan USEPA 3051A metodu seçilmiş̧ir [20]. Reaksiyonlar tamamlandıktan sonra oda sıcaklığına 
gelmesi beklenen örnekler, $0,45 \mu \mathrm{m}$ membran filtreden geçirilerek son hacim ultra saf su ile 50 ml'ye tamamlanmıştır. Ağır metal derişimleri SPECTRO BLUE marka indüktif eşleşmiş plazma optik emisyon spektrometrisi (ICP-OES) kullanılarak 3 tekrarlı olarak ölçülmüştür. Çalışmada $\mathrm{Al}, \mathrm{Fe}, \mathrm{As}, \mathrm{Cr}$, $\mathrm{Ni}, \mathrm{Pb}, \mathrm{Zn}, \mathrm{Cd}, \mathrm{Hg}$ elementlerinin miktarları belirlenmiştir.

\section{4. İstatiksel Analizler}

İstatiksel hesaplamalarda SPSS 20 paket programı kullanılmıştır. Elde edilen verilerin normal dağılıp dağılmadığını belirlemek amacıyla Kolmogorov-Smirnov testi uygulanmıştır. Ağır metal konsantrasyonlarının örnekleme istasyonları arasında ve mevsimler arasında anlamlı bir farklılık sergileyip sergilemediklerini belirlemek için tek yönlü varyans analizi (ANOVA) yapılmıştır. Veriler, varyans homojenliğini sağlamadığı durumda, Tamhane's T2 testi, normal dağılım göstermediği durumda ise Mann Whithney U testi uygulanmıştır.

\section{Bulgular ve Tartışma}

\subsection{Ağır metal seviyelerinin İstasyon ve Mevsimlere Göre Değişimi}

Çalışma periyodu süresince sediment örneklerinde incelenen ağır metallere ait ortalama, standart sapma, minimum ve maksimum değerleri Tablo 2'de verilmiştir. Buna göre Fe tüm istasyonlarda en yüksek konsantrasyonda birikim gösteren element olurken $\mathrm{Hg}, \mathrm{S} 1$ istasyonu hariç en düşük konsantrasyonda belirlenen element olmuştur. S1 istasyonunda en az birikim gösteren element $\mathrm{Cd}$ olarak belirlenmiştir. Yerkabuğunda sirasiyla en fazla bulunan 2. ve 3. element olan $\mathrm{Fe}$ ve Al [21] bütün istasyonlarda en yüksek konsantrasyonda olduğu görülmüştür. As elementi 120,31 $\mu \mathrm{g} / \mathrm{g}$ ile S4 istasyonunda en yüksek konsantrasyonda belirlenmiştir. Yapılan fark analizi sonuçları incelendiğinde As elementinin S4 istasyonunda bütün istasyonlardan anlamlı derece farklı olduğu görülmüştür (One Way ANOVA, p< $0,05)$. Benzer şekilde $\mathrm{Pb}$ değerlerinin de $\mathrm{S} 4$ istasyonunda anlamlı derecede farklı olduğu tespit edilmiştir $(\mathrm{p}<0,05)$. S4 istasyonunda hesaplanan ortalama Pb konsantrasyonu 197,24 $\mu \mathrm{g} / \mathrm{g}$ ile diğer istasyonlarda hesaplanan ortalama $\mathrm{Pb}$ değerlerinden oldukça yüksektir. Cr ve Ni elementlerinin ise S6 istasyonunda diğer tüm istasyonlardan farklı olduğu görülmüştür $(p<0,05)$. $\mathrm{Cr}$ ve $\mathrm{Ni}$ konsantrasyonları S6 istasyonunda sirasıyla 97,84 ve $162,65 \mu \mathrm{g} / \mathrm{g}$ olarak belirlenmiştir. Bu değerler diğer istasyonlara göre oldukça yüksektir. S4 istasyonundaki Al miktarının S1 ve S2 istasyonlarından istatistiksel olarak p<0,05 anlamlılık düzeyinde farklı olduğu belirlenmiştir. Ayrıca S6 istasyonundaki A1 seviyesinin S1, S2 ve S3 istasyonlarından farklı olduğu görülmüştür $(\mathrm{p}<0,05)$. Cd elementine göre istasyonlar arası farklılık incelendiğinde S1 ile S4 istasyonları arasındaki farklılı̆̆ın anlamlı olduğu, S6 istasyonundaki Cd seviyesinin S4 hariç diğer tüm istasyonlardan farklı olduğu belirlenmiştir $(p<0,05)$. $C d$ en yüksek konsantrasyonda $(1,13 \mu \mathrm{g} / \mathrm{g})$ S6 istasyonunda tespit edilmiştir. Fe elementine ait konsantrasyon değerleri S4 istasyonu ile S1 ve S2 istasyonlar1 arasında anlamlı bir farklılık göstermiştir ( $<<0,05)$. Benzer şekilde S6 istasyonu ile S1, S2 ve S3 istasyonları arasında da farklılığın önemli olduğu görülmüş̧ür $(\mathrm{p}<0,05)$. $\mathrm{Zn}$ ve $\mathrm{Hg}$ elementleri açısından istasyonlar arasında anlamlı bir farklılık belirlenmemiştir $(\mathrm{p}<0,05)$.

Çalışmanın gerçekleştirildiği 2013-2014 yılları arasında Kırıkkale ilinin Kızılırmak Havzası'nda yer alan yerleşim yerlerinin hiçbirinde atıksu arıtma tesisi bulunmamaktaydı ve atıksu kanal çıkışında açık akışa geçtikten yaklaşık 50 metre sonra Kızılırmak'a bırakılmaktaydı [16]. Atık suyun Kızılırmak nehrine boşaltıldığı nokta, çalışmanın gerçekleştirildiği istasyonlardan S3 ile S4 arasında yer almaktadır. Buna göre ilk üç istasyon (S1, S2, S3) ve son üç istasyon (S4, S5, S6) karşılaştırıldığında ortalama değerlerin Hg hariç arttığı belirlenmiştir (Tablo 2.). Kanalizasyon suyu ve endüstriyel atıklar genellikle tarım alanlarına ya da nehirlere boşaltılmaktadır. Bu atık sular, zengin bir organik madde kaynağı kabul edilmekle birlikte, alıcı ortamlarda $\mathrm{Fe}, \mathrm{Mn}, \mathrm{Cu}, \mathrm{Zn}, \mathrm{Pb}, \mathrm{Cr}, \mathrm{Ni}, \mathrm{Cd}$ ve Co gibi ağır metal seviyelerini yükselttikleri literatürde belirtilmiştir [22]. Balkhair ve Ashraf (2016) yaptıkları çalışmada, arıtılmamış lağım suyunun ve endüstriyel atıkların toprağa yönelik başlıca kirlilik kaynağı olduğunu ve değişken miktarlarda ağır metal içeren kirli lağım suyu ile sulamanın, topraktaki metallerin konsantrasyonunda ve bu kirlenmiş su kullanılarak yetiştirilen sebzelerde ağır metal miktarının artmasına sebep olduğunu bildirmiştir [23]. Atık noktası öncesi (AO) istasyonlar ile atık noktası sonrası (AS) istasyonlar arasındaki farklılık Mann-Whitney U testi ile incelenmiş iki grup arasındaki farklılık $\mathrm{p}<0,05$ anlamlılık düzeyinde $\mathrm{Zn}$ ve $\mathrm{Hg}$ elementleri hariç anlamlı bulunmuştur. 
Çalışmada elde edilen veriler mevsimsel olarak değerlendirildiğinde bütün mevsimlerde en fazla birikim gösteren elementler $\mathrm{Al}$ ve $\mathrm{Fe}$ olmuştur (Tablo 3). Al, $\mathrm{Fe}, \mathrm{Ni}, \mathrm{Pb}, \mathrm{Cd}$ yaz mevsiminde en fazla birikim gösteren elementler olurken, As, $\mathrm{Zn}$ ve $\mathrm{Hg}$ elementlerinin ilkbaharda daha yüksek konsantrasyonlarda olduğu tespit edilmiştir. Cr element konsantrasyonu yaz ve sonbahar mevsimlerinde birbirine oldukça yakındır. Zn elementi hariç mevsimler arasında önemli bir farklılık tespit edilememiştir $(p<0,05)$. Yapılan Mann Whitney U testi ile $\mathrm{Zn}$ elementi İlkbahar mevsiminde belirlenen $154,46 \mu \mathrm{g} / \mathrm{g}$ konsantrasyon seviyesi ile sonbahar ve kış mevsimlerinden anlamlı derecede farklı bulunmuştur $(\mathrm{p}<0,05)$.

Yapılan çalışma ülkemizdeki göl, nehirler ve barajlarda yapılmış çalışmalardan bazıları ile Tablo 4'de karşılaştıılmıştır. Buna göre, Kankılıç vd. (2013) tarafından yine aynı havza içerisindeki Kapulukaya Barajında gerçekleştirilen çalışmada tespit edilen $\mathrm{Hg}$ değerlerinin daha yüksek olduğu görülmüştür [24]. Baraj içerisindeki iki istasyonda ve barajın aşağı havzasında yer alan Tüpraş Petrol Rafinerisinin Kızılırmak Nehri üzerinde bulunan atık noktası sonransındaki bir istasyondan elde edilen $\mathrm{Cr}$ verilerinin yapılan bu çalışmadaki $\mathrm{Cr}$ değerlerinden oldukça yüksek olduğu görülmüştür. Kızılırmak nehri üzerindeki 6 istasyonda gerçekleştirilen çalışmamızda en yüksek Cr konsantrasyonu $97 \mu \mathrm{g} / \mathrm{g}$ ile S6 istasyonunda belirlenmiştir. Oysaki Kankılıç vd.(2013) tarafindan en yüksek Cr konsantrasyonu 559, $16 \mu \mathrm{g} / \mathrm{g}$ ile petrol rafineri atık noktası sonrasını temsil eden S3 istasyonunda tespit edilmiş̧ir [24]. Kalyoncu vd. (2016) Isparta Deresi'ndeki 6 istasyonda gerçekleştirdikleri çalışmadaki Ni konsantrasyonları S6 istasyonu hariç çalışmamızdaki diğer istasyonlardan daha yüksektir [25]. Dicle Nehri'nde Varol (2011) tarafindan yürütülen çalışmada belirlenen $\mathrm{Cr}, \mathrm{Ni}, \mathrm{Pb}, \mathrm{Zn}$ ve $\mathrm{Cd}$ değerlerinin genellikle çalışmamızdan çok daha yüksek olduğu görülmüştür [19].

\subsection{Sediment Kalite Rehberi İle Değerlendirme}

Sedimentte ağır metallerin birikimi sucul organizmaları negatif yönde etkilerken besin zinciri yoluyla da en üst düzeydeki tüketici olan insana kadar uzanabilen kaçınılmaz bir riski beraberinde getirdiği literatürde bildirilmiştir [26, 27]. Bu nedenle sediment kalite rehberlerinin (SQG) kullanılması, sediment ile birleşen kimyasalların toksikolojik etkilerinin değerlendirilmesinde, sedimentteki mevcut kirlilik durumlarının belirlenmesinde ve korunmasına yönelik önlemlerin alınmasında önemli bir yer teşkil etmektedir. Pek çok çalışmaya ait veriler sediment kalite rehberleri ile karşılaştırılarak mevcut durumun canlılar üzerindeki olası etkileri hakkında değerlendirmeler yapılmıştır [19, 27-30]. Ülkemizde henüz sediment için hazırlanmış bir kalite rehberinin bulunmaması sebebiyle sonuçlarının değerlendirilmesinde MacDonald vd. (2000) tarafindan yayınlanmış sediment kalite rehberindeki Eşik Etki Konsantrasyonu (TEC) ve Olası Etki Konsantrasyonu (PEC) değerleri kullanılmıştır [31]. Bu rehbere göre sedimentte tespit edilen metal miktarı TEC değerinin altındaysa canlılık açısından zararlı etkilerin oluşması beklenmezken, metal konsantrasyon seviyeleri PEC değerinin üstünde tespit edildiğinde, muhtemel zararlı etkilerin açığa çıkabilmesinin söz konusu olabileceği bildirilmiştir [31]. Sediment kirlilik yükünün değerlendirilmesinde kullanılacak olan TEC ve PEC değerleri Tablo 4'de verilmiştir. Buna göre; As değerleri S4 istasyonu hariç PEC değerlerinin altında tespit edilmiştir. S4 istasyonunda oldukça yüksek konsantrasyonda birikimi görülen As canlılık açısından zararlı etkiler açığa çıkarabilir. Cr ve Cd elementlerinin istasyonlarda belirlenen birikim değerlerinin S6 hariç TEC ve PEC değerlerinden düşük olduğu görülmüştür. S6 istasyonunda ise iki değer arasında kaldığı tespit edilmiştir. Bu durum S6 istasyonunda potansiyel zararlı etkilerin açığa çıkabileceğinin sinyallerini vermektedir. Ni birikimi incelendiğinde $\mathrm{S} 1$ ve $\mathrm{S} 2$ hariç tespit edilen değerlerin PEC değerinden yüksek olduğu görülmüştür. $\mathrm{Pb}$ ve $\mathrm{Zn}$ elementleri ise $\mathrm{S} 4$ hariç TEC ve $\mathrm{PEC}$ değerlerinden düşük konsantrasyonlarda birikim göstermiştir. Hg değerleri ilk üç istasyonda TEC ve PEC değerleri arasında kalırken son üç istasyonda bu iki değerden düşük konsantrasyonlarda birikim sergilemişlerdir.

Tablo 2. İstasyonlardan alınan sediment örneklerindeki ağır metal konsantrasyonlarının ortalama, standart sapma, minimum ve maksimum değerleri $(\mu \mathrm{g} / \mathrm{g})$ 


\begin{tabular}{|c|c|c|c|c|c|c|c|}
\hline & & S1 & S2 & S3 & $\mathrm{S4}$ & S5 & S6 \\
\hline \multirow{3}{*}{ Al } & Ort & 2212,00 & 2240,84 & 2770,43 & 3509,37 & 3260,18 & 4279,91 \\
\hline & Std Sp & 567,54 & 107,15 & 415,05 & 433,06 & 699,27 & 491,79 \\
\hline & Min-Maks & $1757,52-3041,79$ & $2111,81-2374$ & $2484,91-3386,82$ & $3014,13-3987,89$ & $2827,71-4304,73$ & $3779,31-4919,43$ \\
\hline \multirow{3}{*}{$\mathbf{F e}$} & Ort & 7093,82 & 7419,88 & 9000,99 & 13131,44 & 11257,06 & 16282,23 \\
\hline & Std. Sp. & 2229,66 & 3513,07 & 1245,73 & 2168,17 & 3078,59 & 493,61 \\
\hline & Min-Maks & $5080,87-9693,61$ & $4605,40-12461,70$ & $7753,53-10517,70$ & $9897,97-14488,00$ & $8832,76-15715,40$ & $15656,20-16832,70$ \\
\hline \multirow{3}{*}{ As } & Ort & 7,63 & 9,16 & 15,70 & 120,31 & 16,48 & 10,33 \\
\hline & Std. Sp. & 2,71 & 3,48 & 2,91 & 91,96 & 4,46 & 1,75 \\
\hline & Min-Maks & $6,12-11,69$ & $5,71-13,97$ & $12,77-19,44$ & $30,16-237,74$ & $10,61-20,49$ & $8,00-11,74$ \\
\hline \multirow{3}{*}{$\mathrm{Cr}$} & Ort & 15,09 & 18,78 & 19,88 & 28,89 & 33,22 & 97,84 \\
\hline & Std. Sp. & 7,84 & 4,88 & 4,49 & 7,81 & 9,12 & 10,40 \\
\hline & Min-Maks & $8,31-26,23$ & $15,26-25,99$ & $15,37-25,94$ & $20,77-39,50$ & $25,02-45,93$ & $82,61-106,04$ \\
\hline \multirow{3}{*}{$\mathbf{N i}$} & Ort & 43,57 & 37,29 & 49,34 & 61,13 & 58,56 & 162,65 \\
\hline & Std. Sp. & 35,31 & 6,13 & 23,55 & 13,98 & 21,54 & 22,24 \\
\hline & Min-Maks & $16,83-95,54$ & $29,00-42,47$ & $30,97-83,86$ & $48,74-63,57$ & $41,46-87,82$ & $140,62-184,24$ \\
\hline \multirow{3}{*}{$\mathbf{P b}$} & Ort & 6,33 & 8,17 & 11,41 & 197,24 & 14,08 & 13,42 \\
\hline & Std. Sp. & 1,13 & 5,94 & 2,83 & 137,52 & 6,04 & 5,36 \\
\hline & Min-Maks & $5,48-8,00$ & $4,31-17,02$ & $7,39-13,50$ & $34,39-331,44$ & $7,35-20,88$ & $8,21-20,60$ \\
\hline \multirow{3}{*}{$\mathbf{Z n}$} & Ort & 39,50 & 64,54 & 89,32 & 167,51 & 58,15 & 71,29 \\
\hline & Std. Sp. & 33,94 & 62,79 & 91,23 & 106,61 & 31,48 & 30,55 \\
\hline & Min-Maks & $23,89-90,35$ & $28,82-158,58$ & $28,44-221,85$ & $72,10-317,87$ & $30,20-91,61$ & $39,82-112,97$ \\
\hline \multirow{3}{*}{$\mathrm{Cd}$} & Ort & 0,25 & 0,29 & 0,38 & 0,75 & 0,62 & 1,13 \\
\hline & Std. Sp. & 0,15 & 0,19 & 0,09 & 0,18 & 0,33 & 0,26 \\
\hline & Min-Maks & $0,11-0,44$ & $0,15-0,56$ & $0,28-0,44$ & $0,52-0,96$ & $0,36-1,10$ & $0,87-1,48$ \\
\hline \multirow{3}{*}{$\mathbf{H g}$} & Ort & 0,55 & 0,24 & 0,19 & 0,13 & 0,12 & 0,11 \\
\hline & Std. Sp. & 0,85 & 0,23 & 0,13 & 0,07 & 0,05 & 0,04 \\
\hline & Min-Maks & $0,11-1,82$ & $0,10-0,58$ & $0,11-0,37$ & $0,07-0,24$ & $0,09-0,19$ & $0,06-0,16$ \\
\hline
\end{tabular}


Tablo 3. Sediment örneklerinde belirlenen ağır metal konsantrasyonlarının mevsimsel değerleri (Ort: Ortalama, Std. Sp.: Standart sapma, Min: Minimum, Maks.: Maksimum) ( $\mu \mathrm{g} / \mathrm{g}$ kuru ağırlık).

\begin{tabular}{|c|c|c|c|c|c|}
\hline & & İlkbahar & Yaz & Sonbahar & Kiș \\
\hline \multirow{3}{*}{ Al } & Ort & 3031,36 & 3416,64 & 2957,52 & 2776,29 \\
\hline & Std. Sp. & 1138,96 & 787,90 & 880,95 & 678,96 \\
\hline & Min-Maks & $1757,52-4919,43$ & $2374,05-4378,30$ & $2004,99-4042,61$ & $2043,68-3779,31$ \\
\hline \multirow{3}{*}{$\mathbf{F e}$} & Ort & 10213,90 & 11970,77 & 11502,16 & 9103,45 \\
\hline & Std. Sp. & 4914,21 & 4162,72 & 3318,64 & 3557,52 \\
\hline & Min-Maks & $4605,40-16382,70$ & $5530,60-16448,80$ & $8202,37-16191,20$ & $5398,41-15656,20$ \\
\hline \multirow{3}{*}{ As } & Ort & 49,58 & 35,54 & 20,46 & 14,16 \\
\hline & Std. Sp. & 92,41 & 54,22 & 23,15 & 8,55 \\
\hline & Min-Maks & $5,71-237,74$ & $8,09-145-92$ & $6,41-67,42$ & $6,29-30,16$ \\
\hline \multirow{3}{*}{$\mathrm{Cr}$} & Ort & 34,45 & 37,36 & $37,99 \pm$ & 32,67 \\
\hline & Std. Sp. & 36,27 & 24,15 & 32,16 & 34,06 \\
\hline & Min-Maks & $8,31-106,04$ & $16,65-82,61$ & $14,51-101,16$ & $11,31-101,56$ \\
\hline \multirow{3}{*}{$\mathbf{N i}$} & Ort & 58,85 & 85,65 & 72,89 & 57,64 \\
\hline & Std. Sp. & 62,45 & 33,10 & 54,77 & 44,21 \\
\hline & Min-Maks & $16,83-184,24$ & $42,47-140,62$ & $32,75-179,18$ & $29,17-146,54$ \\
\hline \multirow{3}{*}{$\mathbf{P b}$} & Ort & 56,81 & 65,04 & 33,78 & 11,47 \\
\hline & Std. Sp. & 113,53 & 130,63 & 49,73 & 11,27 \\
\hline & Min-Maks & $5,33-288,37$ & $4,31-331,44$ & $5,94-134,76$ & $5,48-34,39$ \\
\hline \multirow{3}{*}{$\mathbf{Z n}$} & Ort & 154,46 & 84,49 & 51,34 & 36,57 \\
\hline & Std. Sp. & 103,91 & 41,68 & 36,92 & 18,50 \\
\hline & Min-Maks & $23,89-317,87$ & $36,94-160,94$ & $23,71-119,14$ & $20,07-72,10$ \\
\hline \multirow{3}{*}{ Cd } & Ort & 0,63 & 0,67 & 0,58 & 0,40 \\
\hline & Std. Sp. & 0,51 & 0,38 & 0,30 & 0,26 \\
\hline & Min-Maks & $0,15-1,48$ & $0,15-1,10$ & $0,29-1,09$ & $0,11-0,87$ \\
\hline \multirow{3}{*}{ Hg } & Ort & 0.56 & 0,13 & 0.09 & 0,11 \\
\hline & Std. Sp. & 0,64 & 0,02 & 0,02 & 0,01 \\
\hline & Min-Maks & $0,16-1,82$ & $0,10-0,16$ & $0,06-0,11$ & $0,09-0,13$ \\
\hline
\end{tabular}


Tablo 4. Çalışma periyodu süresince sedimentte tespit edilen ortalama ağır metal konsantrasyonlarının Türkiye'de yapılmış diğer çalışmaların ortalama değerleri ve sediment kalite rehberi (SQG) ile karşılaştırılması ( $\mu \mathrm{g} / \mathrm{g}$ kuru ağırlık).

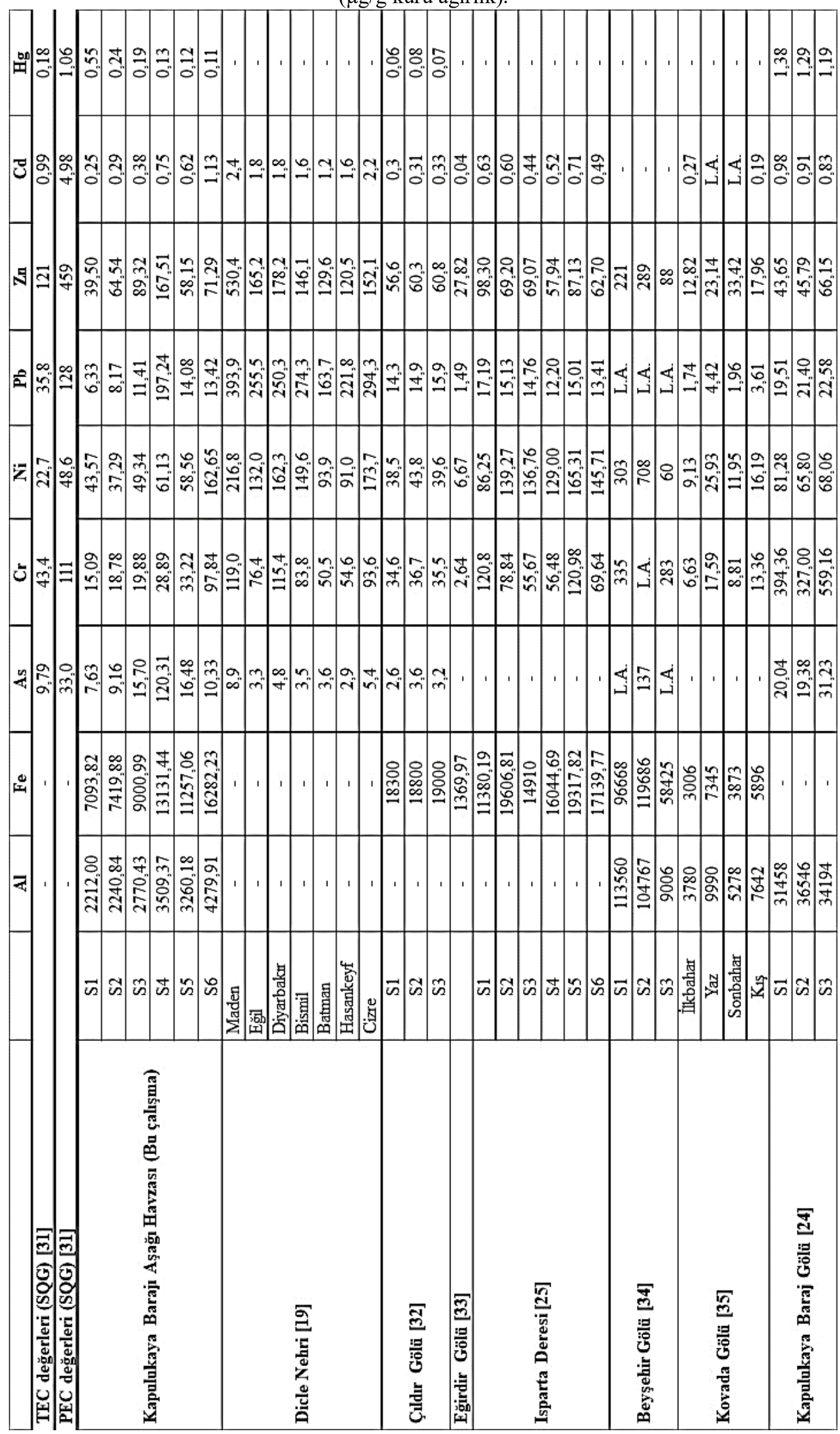



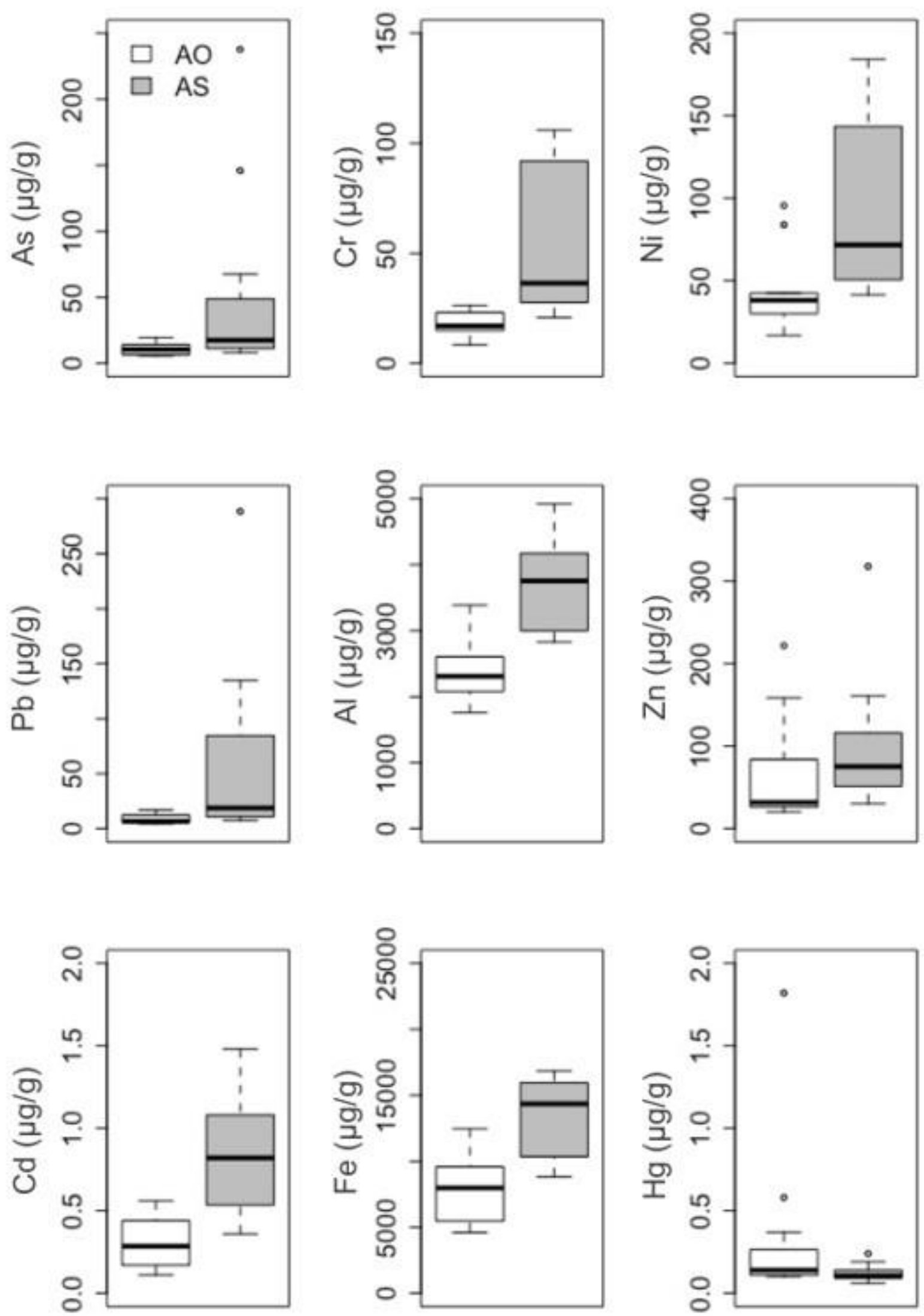

Şekil 2. Atık öncesi (AO) (S1, S2, S3 istasyonları) ve atık sonrası (AS) (S4, S5, S6 istasyonları) ağır metal konsantrasyonlarının karşılaştırılması (Her bir element için Y eksen değerleri farklı aralıklarda kullanılmıştır). 


\section{Sonuç}

Yapılan çalışma ile Kızılırmak Nehri'nin Kırıkkale il sınırları içerisinde kalan kısmındaki ağır metal kirlilik yükü ortaya konulmuştur. Buna göre atık suyun bırakıldığ ortalama değerlerin $\mathrm{Hg}$ hariç artış gösterdiği belirlenmiştir. Bu sonuçlar istasyonlar arasında farklılık göstermekle birlikte genel olarak As, Ni, element konsantrasyonlarının sedimentte sıklıkla yaşayan ve sedimentten beslenen organizmalar üzerinde zararlı etkilere yol açabileceğini göstermiştir. Bu çalışma ile sedimentten elde edilen bulgulara dayanarak, bölgedeki belirli elementlere ait ağır metal kirlilik seviyesi açıkça değerlendirmiştir.

\section{Teşekkür}

Bu çalışma, Kırıkkale Üniversitesi Bilimsel Araştırma Birimi (KKU BAP, Proje No: 2012/31) kapsamında gerçekleştirilen projenin yürütüldüğü alanda ve zaman diliminde gerçekleştirilmiştir. $\mathrm{Bu}$ çalışma doğrultusunda alınan örneklemler, proje kapsamı dışındadır.

\section{Kaynaklar}

[1] Xu F., Liu Z., Cao Y., Qiu L., Feng J., Xua F., Tian X. 2017. Assessment of heavy metal contamination in urban river sediments in the Jiaozhou Bay catchment, Qingdao, China. Catena, 150: 9-16.

[2] Desaules A. 2012. Critical evaluation of soil contamination assessment methods for trace metals Science of the Total Environment, 426: 120-131.

[3] Teng Y.G., Wu J., Lu S.J., Wang Y.Y., Jiao X.D., Song L.T. 2014. Soil and soil environmental quality monitoring in China: a review. Environment International, 69: 177-199.

[4] Yuan C., Shi J., He B., Liu J., Liang L., Jiang G. 2004. Speciation of heavy metals in marine sediments from the East China sea by ICP-MS with sequential extraction. Environment International, 30: 769-783.

[5] Bjerregaard P., Andersen O. 2007. Ecotoxicology of Metals-Sources,Transport, and Effects in the Ecosystem in Handbook on the Toxicology of Metals. Elsevier Press, 251-277.

[6] Liu J., Yin P., Chen B., Gao F., Song H., Li M. 2016. Distribution and contamination assessment of heavy metals in surface sediments of the Luanhe River Estuary, northwest of the Bohai Sea. Marine Pollution Bulletin, 109: 633-639.

[7] Zhuang W., Gao X. 2015. Distributions, sources and ecological risk assessment of arsenic and mercury in the surface sediments of the southwestern coastal Laizhou Bay, Bohai Sea. Marine Pollution Bulletin, 99: 320-327.

[8] Pham N.T.T., Pulkownik A., Buckney R.T. 2007. Assesment of heavy metals in sediments and aquatic organisms in West Lake (Ho Tay), Hanoi, Vietnam. Lake \& Reservoirs: Research and Management, 12: 285-294.

[9] Peng K., Luo C., Lou L., Li X., Shen Z. 2008. Bioaccumulation of heavy metals by the aquatic plants Potamogeton pectinatus L. and Potamogeton malaianus Miq. And their potential use for contamination indicators and in wastewater treatment. Science of the Total Environment, 392: 22-29.

[10] Fu K., Su B., He D., Lu X., Song J., Huang J. 2012. Pollution assessment of heavy metals along the Mekong River and dam effects. Journal of Geographical Sciences, 22 (5): 874-884

[11] Antizar-Ladislao B,, Mondal P., Mitra S., Sarkar S.K. 2015. Assessment of trace metal contamination level and toxicity in sediments from coastal regions of West Bengal, eastern part of India. Marine Pollution Bulletin, 101: 886-894.

[12] Zoumis T., Schmidt A., Grigorova L., Calmano W. 2001. Contaminants in sediments: remobilization and demobilization. Science of the Total Environment, 266: 195-202.

[13] Karadede H., Ünlü E. 2000. Concentrations of some heavy metals in water, sediment and fish species from the Atatürk Dam Lake (Euphrates), Turkey. Chemosphere, 41: 1371-1376.

[14] Shen G., Lu Y., Wang M., Sun Y. 2005. Status and fuzzy comprehensive assessment of combined heavy metal and organo-chlorine pesticide pollution in Taihu Lake region of China. Journal of Environmental Management, 76: 355-362. 
[15] USEPA, 2001. Methods for Collection, Storage and Manipulation of Sediments for Chemicaland Toxicological Analyses: Technical Manual.

[16] TÜBITAK MAM ÇEVRE ENSTITÜSÜ, 2013. Havza Koruma Eylem Planı Final RaporuKızılırmak Havzas1 529 pp.

[17] Brekken A., Steinnes E. 2004. Seasonal concentrations of cadmium and zinc in native pasture plants: consequences for grazing animals. Science of the Total Environment, 326: 181-195.

[18] Teuchies J., De Deckere E., Bervoets L., Meynendonckx J., Van Regenmortel S., Blust R., Meire P. 2007. Influence of tidal regime on distribution of trace metals in a contaminated tidal freshwater marsh soil colonized with common reed (Phragmites australis). Environmental Pollution, 155 (1): 20-30.

[19] Varol M. 2011. Assessment of heavy metal contamination in sediments of the Tigris River (Turkey) using pollution indices and multivariate statistical techniques. Journal of Hazardous Materials, 195: 355-364.

[20] USEPA, 2007. Method 3051a: Microwave Assisted Acid Dissolution of Sediments, Sludges, Soils, and Oils, Revision 1, United States Environmental Protection Agency, Washington, DC.

[21] Jaishankar M., Tseten T., Anbalagan N., Mathew B.B., Beeregowda K.N. 2014. Toxicity, mechanism and health effects of some heavy metals. Interdisciplinary Toxicology, 7 (2): 60-72.

[22] Rattan R.K., Datta S.P., Chhonkar P.K., Suribabu K., Singh A.K. 2005. Long-term impact of irrigation with sewage effluents on heavy metal content in soils, crops and groundwater-a case study. Agriculture, Ecosystems \& Environment, 109 (3-4): 310-322.

[23] Balkhair K.S., Ashraf M.A. 2016. Field accumulation risks of heavy metals in soil and vegetable crop irrigated with sewage water in western region of Saudi Arabia. Saudi Journal of Biological Sciences, 23: S32-S44.

[24] Kankılıç G.B., Tüzün İ., Kadığlu Y.K. 2013. Assessment of heavy metal levels in sediment samples of Kapulukaya Dam lake (Kirikkale) and lower catchment area. Environ-mental Monitoring and Assessment, 185 (8): 6739-6750.

[25] Kalyoncu H., Özan C., Tekin-Özan S. 2016. Isparta Deresi'nin Su ve Sedimentlerindeki Ağır Metal Birikiminin İncelenmesi. Mehmet Akif Ersoy Üniversitesi Fen Bilimleri Enstitüsü Dergisi, 7 (1): 268-280.

[26] Cheung K.C., Poon B.H.T., Lan C.Y., Wong M.H. 2003. Assessment of metal and nutrient concentrations in river water and sediment collected fromthe cities in the Pearl River Delta, South China. Chemosphere, 52: 1431-1440.

[27] Hang X., Wang H., Zhou J., Du C., Chen X. 2009. Characteristics and accumulation of heavy metals in sediments originated from an electroplating plant. Journal of Hazardous Materials, 163: 922-930.

[28] Farkas A., Erratico C., Viganó L. 2007. Assessment of the environmental significance of heavy metal pollution in surficial sediments of the River Po. Chemosphere, 68: 761-768.

[29] Salati S., Moore-F. 2010. Assessment of heavy metal concentration in the Khoshk River water and sediment, Shiraz, Southwest Iran. Environmental Monitoring and Assessment, 164: 677-689.

[30] Zhang Z., Lu Y., Li H., Tu Y., Liu, B. Yang Z. 2018. Assessment of heavy metal contamination, distribution and source identification in the sediments from the Zijiang River. China. Science of the Total Environment, 15 (645): 235-243.

[31] MacDonald D.D., Ingersoll C.G., Berger T.A. 2000. Development and evaluation of consensusbased sediment quality guidelines for freshwater ecosystems. Archives of Environmental Contamination and Toxicology, 39: 20-31.

[32] Kükrer S., Şeker S., Abacı Z.T ., Kutlu B. 2014. Ecological risk assessment of heavy metals in surface sediments of northern littoral zone of Lake Çıldır, Ardahan, Turkey. Environmental monitoring and assessment, 186 (6): 3847-3857.

[33] Kaptan H., Tekin-Özan S. 2014. Eğirdir Gölü'nün (Isparta) Suyunda, Sedimentinde ve Gölde Yaşayan Sazan'ın (Cyprinus carpio L., 1758) Bazı Doku ve Organlarındaki Ağır Metal Düzeylerinin Belirlenmesi. SDU Journal of Science (E-Journal), 9 (2): 44-60.

[34] Tunca E.Ü. 2016. Beyşehir Gölü'nde Su ve Sedimentte Ağır Metal Birikimi ve Sedimentte Antropojenik Kontaminasyon Değerlendirmesi. Ordu Üniversitesi Bilim ve Teknoloji Dergisi, 6 (2): 205-219.

[35] Kır İ., Tekin Özan S., Tuncay Y. 2007. Kovada Gölü’nün Su ve Sedimentindeki Bazı Ağır Metallerin Mevsimsel Değişimi. Ege Üniversitesi Su Ürünleri Dergisi, 24 (1-2): 155-158. 